\title{
Estimation of Global Solar Radiation for Four Selected Sites in Nepal Using Sunshine Hours, Temperature and Relative Humidity
}

\author{
Krishna R. Adhikari ${ }^{1 *}$, Binod K. Bhattarai ${ }^{1}$, Shekhar Gurung ${ }^{2}$ \\ ${ }^{1}$ Institute of Engineering, Tribhuvan University, Kathmandu, Nepal; ${ }^{2}$ Central Department of Physics, Tribhuvan University, Kath- \\ mandu, Nepal. \\ Email: ${ }^{*}$ adhikari.krishnaraj@gmail.com
}

Received August $9^{\text {th }}, 2013$; revised August $23^{\text {rd }}, 2013$; accepted August $30^{\text {th }}, 2013$

Copyright (C) 2013 Krishna R. Adhikari et al. This is an open access article distributed under the Creative Commons Attribution License, which permits unrestricted use, distribution, and reproduction in any medium, provided the original work is properly cited.

\begin{abstract}
Rational and accurate solar energy databases, essential for designing, sizing and performing the solar energy systems in any part of the world, are not easily accessible in different localities of Nepal. In this study, daily global solar radiation, sunshine hours and meteorological data for Biratnagar, Kathmandu, Pokhara and Jumla have been used to derive the regression constants. The linear regression technique has been used to develop a model for Biratnagar, Kathmandu, Pokhara and Jumla. The model has calculated the global solar radiation for these locations. The values of global solar radiation estimated by the model are found to be in close agreement with measured values of respective sites. The estimated values were compared with Angstrom-Prescott model and examined using the root mean square error (RMSE), mean bias error (MBE), mean percentage error (MPE), coefficient of regression (R), coefficient of determinant $\left(\mathrm{R}^{2}\right)$ and correlation coefficient (CC) statistical techniques. Thus, the resultant correlations and linear regression relations may be then used for the locations of similar meteorological/geographical characteristics and also can be used to estimate the missing data of solar radiation for the respective site.
\end{abstract}

Keywords: Global Solar Radiation; Clearness Index; Sunshine Hours; Linear Regression Relation; Model

\section{Introduction}

Nepal is a land-locked mountainous country with a large area of beautiful landscape situated between $26^{\circ} 22^{\prime}$ to $30^{\circ} 27^{\prime}$ North latitude and $80^{\circ} 40^{\prime}$ to $80^{\circ} 12^{\prime}$ East longitude within a span of $200 \mathrm{~km}$ from south to north and about $800 \mathrm{~km}$ from east to west [1]. The total area of the country is 147,181 square kilometers and is divided into five physiographic regions: High Himal, High Mountain, Middle Mountain, Siwalik (the Chure Range) and the Terai [2].

Nepal has more than 6000 rivers with all river systems draining north to south towards the Ganges [2] and its theoretical, technical and economically feasible hydropower potential has been estimated at about $83,000 \mathrm{MW}$, 45,000 MW and 42,000 MW respectively [1]. The current installed capacity of power plants connected to the national grid is $689 \mathrm{MW}$ whereas peak demand of power for the year of 2011 was $946.10 \mathrm{MW}$ and projection of

"Corresponding author. power demand for 2012/2013 was 1163.2 MW [3]. The electricity consumption and the number of consumers increase at a rate of approximately 9\% per year [4] whereas generation of additional power plant is almost in stagnant situation. This gap between supply and demand in power sector forces Nepal Electricity Authority into load-shedding from 4 hours to 16 hours per day in spring and dry season respectively [5].

With the rapid use and depletion of fossil fuel reserves [6] in the world, they create negative impact on economy and environment [7]. The construction period for new power generation projects and new import transmission capacities is very long, therefore, a rapid improvement of energy supply cannot be expected. An urgent supply of power through diesel power plants is impracticable because of the high power generation costs. The power supply crisis affects public life and especially economic development negatively [4]. Moreover, biomass technology does not work well enough on the comparatively cold high altitude and small hydro turbines need special 
topographical conditions [1] to be established and run. All the above facts demand a shift of the emphasis to the new and clean alternative energy sources to replace costly and unrealistic sources and ensure sustainable development of the country.

In the year of 2008/2009, total energy consumption in Nepal was 401 million GJ, out of $87 \%$ of total energy consumption was derived from traditional resources (also called biomass energy resources), $12 \%$ from commercial sources (coal, grid electricity, and petroleum products) and less than $1 \%$ from the alternative sources (biogas, solar power, wind and micro/pico level hydropower) [1]. The average global solar radiation in Nepal varies from $3.6-6.2 \mathrm{kWh} / \mathrm{m}^{2} \cdot$ day; the sun shines for about 300 days a year, the national average sunshine duration is 6.8 hours/day and average insolation intensity about 4.7 $\mathrm{kWhm}^{-2} \cdot$ day $^{-1}\left(=16.92 \mathrm{MJ} / \mathrm{m}^{2}\right.$. day) [1], it is greater than the $15.8 \mathrm{MJ} / \mathrm{m}^{2}$. day measured by Solar Energy Research Laboratory, Department of Physics, Silpakorn University, Thailand for Lao PDR [7]. The data is based on one year's several sites of Nepal. With the consideration of $12 \%$ efficiency of PV module and $4.7 \mathrm{kWh} / \mathrm{m}^{2} \cdot$ day $^{1}$ of insolation intensity, the total energy generation potential of the country will be $83,000 \mathrm{GWh} /$ day $=18.36 \mathrm{TW}$. This is more than present energy demand (13 TW) of the world [1]. Under this circumstance, the development of solar energy technology in many parts of the country and especially in rural sectors is desirable and favorable where there is no viable alternative to the solar electricity [1].

Choice of solar energy, in countries like Nepal, is the best and ultimate option among the different energy including alternative energy sources. If we think of complete solution of rural electrification in Nepal, we have to plan to link up micro-hydro/pico-hydro with solar energy exploitation. Thus, an accurate knowledge and database of solar radiation at a particular place and selected sites are important for the development of many solar devices, the establishment of solar plant at the proposed site and for estimation of their performance [8].

The radiation reaching the earth surface is modified significantly by clouds [9], water vapor, ice, aerosols, and atmospheric constituents in its intensity and the sunshine duration. The beam radiation (radiation coming directly from the solar disk) is attenuated by the presence of cloud in its path, as well as by the various atmospheric elements. The depletion of the direct beam by the cloud depends on the type of clouds, their thickness and the number of layers [10]. The radiation scattered by the atmospheric constituents is called diffuse radiation where a portion of this radiation goes back by about $6 \%$ of the incident radiation to space, and a portion, about $20 \%$ of the incident radiation, reaches the earth surface [11]. The sum of direct and diffuse radiation on the earth surface is known as global/total radiation which is very important for the design of certain solar energy applications [10].

In developing countries like Nepal, the facility of ground-based measurement of solar radiation is available only at selected sites whereas meteorological and hydrological data are available at different parts of the country. Obviously the best way of knowing the amount of global solar radiation at the site of consideration is to install pyranometer at many locations in the given region and look after their day-to-day maintenance and recording, which is a very expensive venture. The alternative approach is to correlate the global radiation with the meteorological parameters where the data can be collected. The resultant correlation may then be used for locations of similar meteorological characteristics [12]. Thus, developing the empirical model to estimate the global solar radiation using easily available parameters such as sunshine duration, maximum and minimum temperature, relative humidity, rainfall and geographical location, etc., is an essential assignment for countries like Nepal, which will be a vigorous scientific research. So far, various models have been developed by a number of researchers with different regression coefficients using linear regression techniques [13] for various countries and for different locations to estimate solar radiation. The most and commonly used model in most of the countries including Nepal is Angstrom-Prescott model which is based on correlation of global solar radiation with sunshine hours.

Available literatures show that there is a very few and limited study done in Nepal to develop the model and to calculate the regression coefficients. This may be due to inadequacy of existing solar energy data and lacking sense of necessity to develop solar energy techniques. Either the researchers may have been satisfied with the available data or our research culture may be such that the research works are not well tied up with our ground reality.

Empirical models which have been used to calculate solar radiation are usually based on astronomical factors, geographical factors, geometric factors, physical factors and meteorological factors [14].

In the present study, annual radiation, meteorological/ hydrological data have been used to derive the regression coefficients $b, c, d$ and intersection constant $a$ to develop a model based on linear regression technique to estimate the monthly average daily global solar radiation for four sites of Nepal, and to compare the values with the estimations derived from sunshine-based Angstrom-Prescott model. The linear regression relation of the model is

$$
\frac{\bar{H}_{m}}{\bar{H}_{O}}=a+b\left(\frac{\bar{n}}{\bar{N}_{d}}\right)+c\left(\frac{\bar{T}_{a v}}{\bar{T}_{M}}\right)+d \ln (\overline{R H})
$$

where $\bar{H}_{m}$ is measured monthly mean daily solar ra- 
diation on horizontal surface in $\mathrm{MJ} / \mathrm{m}^{2} \cdot$ day, $\bar{H}_{O}$ monthly mean daily extraterrestrial radiation on horizontal surface in $\mathrm{MJ} / \mathrm{m}^{2}$.day, $\bar{n}$ monthly mean daily sunshine hours, $\bar{N}_{d}$ monthly average maximum possible daily hours of sunshine or the day length, $\bar{T}_{a v}$ and $\bar{T}_{M}$ are monthly mean of daily mean and monthly mean daily maximum temperature in Kelvin scale, $\overline{R H}$ monthly mean daily relative humidity, $\ln$ natural logarithm and $a$, $b, c, d$ are constants obtained by the linear regression analysis.

\section{Material and Method}

The primary data of daily solar radiation on horizontal surface for Biratnagar, Kathmandu, Pokhara and Jumla were collected from the archives of the Department of Hydrology and Meteorology, government of Nepal (DHM/GoN) and Solar Radiation and Aerosol in Himalayan Region (SAHR) project of Institute of Engineering, Tribhuvan University, Nepal. Daily sunshine duration, temperature and relative humidity data for these sites were obtained from Department of Hydrology and Meteorology $(\mathrm{DHM}) / \mathrm{GoN}$. The data obtained covered a period of years from 2007 to 2012 for Biratnagar (latitude $26.483^{\circ}$, longitude $87.266^{\circ}$ and altitude $72 \mathrm{~m}$ ), Kathmandu (latitude $27.7^{\circ}$, longitude $86.366^{\circ}$ and altitude $1337 \mathrm{~m}$ ), Pokhara (latitude $28.216^{\circ}$, longitude $84^{\circ}$ and altitude $827 \mathrm{~m}$ ) and two years 2011 to 2012 years for Jumla (latitude $29.283^{\circ}$, longitude $82.166^{\circ}$ and altitude $2300 \mathrm{~m})$. The most widely used ORIGIN/Microsoft Office Excel softwares have been used for the data analysis.

\subsection{Theory}

The acquired data were processed in Microsoft Office Excel to obtain useful form i.e., daily extraterrestrial solar radiation in $\mathrm{MJ} / \mathrm{m}^{2}$, daily global radiation in $\mathrm{MJ} / \mathrm{m}^{2}$, the ratio of daily mean of maximum and minimum temperature to daily maximum temperature in Kelvin scale and natural logarithm of average value of daily relative humidity data of the year 2007-2012 for Biratnagar, Kathmandu and Pokhara and those of 2011-2012 data for Jumla.

The proposed linear regression relation (empirical model) to estimate global solar radiation is given below:

$$
\frac{\bar{H}_{m}}{\bar{H}_{O}}=a+b\left(\frac{\bar{n}}{\bar{N}_{d}}\right)+c\left(\frac{\bar{T}_{a v}}{\bar{T}_{M}}\right)+d \ln (\overline{R H})
$$

where, $a, b, c$, and $d$ are regression constants, the ratio $\frac{\bar{H}_{m}}{\bar{H}_{O}}$ is clearness parameter or cloudiness index, $\left(\frac{\bar{n}}{\bar{N}_{d}}\right)$ fraction of sunshine hours, and

$\bar{H}_{O}$ is the monthly average daily extraterrestrial radia- tion on the horizontal surface given by Iqbal (1983) as follows:

$$
\bar{H}_{O}=\frac{24}{\pi} I_{s c} E_{o}\left[\frac{\pi}{180} \omega_{s} \sin \phi \sin \delta+\cos \phi \cos \delta \sin \omega_{s}\right]
$$

where,

$$
I_{s c}=\frac{1367 \times 3600}{1000000} \mathrm{MJ} / \mathrm{m}^{2} \cdot \mathrm{h}^{1}
$$

is the solar constant,

$$
E_{o}=1+0.33 \cos \frac{360 N}{365}
$$

is the eccentricity correction,

$N$ is the day number of the year (DoY)/Julian day (1 Jan, $N=1$ and 31st December, $N=365$ ), $\phi$ is the latitude of the site,

$$
\delta=23.45 \sin \left[\frac{360(N+284)}{365}\right]
$$

is the solar declination,

$$
\omega_{s}=\cos ^{-1}(-\tan \phi \tan \delta)
$$

is the hour angle,

$$
N_{d}=\frac{2}{15} \cos ^{-1}(-\tan \phi \tan \delta)=\frac{2}{15} \omega_{s}
$$

is the maximum possible sunshine hours.

\subsection{Developing a Model}

The data presented in Table 1 has been used to evaluate the regression constants $a, b, c$ and $d$ for the year mentioned in the table and the same technique used for other years too. Three years' values were averaged to derive the final regression constants presented in Table 2.

To analyze these data further, the first order linear regression equation was employed as given below:

$$
a+b x+c y+d z=K_{T}
$$

It is an equation of least square line [15] or first order regression [16] where, $K_{T}\left(=H_{m} / H_{o}\right)$ is a dependent variable called clearness index, $a, b, c, d$ are regression constants, and

$$
x=\left(\frac{n}{N_{d}}\right), y=\left(\frac{T_{a v}}{T_{M}}\right), z=\ln (R H)
$$

are independent variables and the earlier explained meteorological parameters.

To perform the regression analysis of least square line, both sides of the Equation (8) have to be multiplied by 1, $x, y$ and $z$ successively and summing both sides to obtain: 
Table 1. One year sum of different metrological parameters for four sites in Nepal to derive regression constants and used meteorological data of the years.

\begin{tabular}{ccccccc}
\hline Locations & $\sum n / N_{d}$ & $\sum T_{a v} / T_{M}$ & $\sum \ln (R H)$ & $\sum K_{T}=H_{m} / H_{O}$ & Used 1 Year Data & Data of Years \\
\hline Biratnagar & 188.722 & 358.554 & 1579.288 & 171.751 & 2010,365 days & $2007,2008,2010$ \\
Kathmandu & 198.129 & 356.3063 & 1574.593 & 175.878 & 2010,365 days & $2007,2008,2010$ \\
Pokhara & 202.645 & 358.0092 & 1561.1 & 197.246 & 2010,365 days & $2008,2010,2012$ \\
Jumla & 221.566 & 354.8842 & 1487.16 & 227.936 & 2011,365 days & 2011,2012 \\
\hline
\end{tabular}

Table 2. Regression constants, comparison of errors and regression coefficient for different models and sites.

\begin{tabular}{|c|c|c|c|c|c|c|c|c|c|c|c|c|c|c|c|c|}
\hline \multirow{2}{*}{$\mathrm{SN}$} & \multirow{2}{*}{ Locations } & \multicolumn{4}{|c|}{ Regression constants } & \multicolumn{2}{|c|}{ RMSE } & \multicolumn{2}{|c|}{ MBE } & \multicolumn{2}{|c|}{ MPE\% } & \multicolumn{2}{|c|}{$\mathrm{R}$} & \multicolumn{2}{|c|}{$\mathrm{R}^{2}$} & \multirow{2}{*}{$\frac{\mathrm{CC}}{\mathrm{New}}$} \\
\hline & & $a$ & $b$ & $c$ & $d$ & Ang & New & Ang & New & Ang & New & Ang & New & Ang & New & \\
\hline 1 & Biratnagar & $-2 \mathrm{E}-07$ & 0.162 & 1.032 & -0.168 & 1.94 & 0.86 & -0.873 & -0.10 & 6.31 & 0.79 & 0.81 & 0.956 & 0.66 & 0.914 & 0.96 \\
\hline 2 & Kathmandu & $-1 \mathrm{E}-04$ & 0.324 & -0.09 & 0.08 & 4.15 & 1.197 & -2.32 & 0.866 & 11.52 & 0.34 & 0.7 & 0.948 & 0.44 & 0.898 & 0.93 \\
\hline 3 & Pokhara & $-8 \mathrm{E}-06$ & 0.337 & -0.21 & 0.120 & 2.82 & 0.750 & -0.6 & -0.14 & 2.35 & 1.0248 & 0.61 & 0.97 & 0.37 & 0.94 & 0.99 \\
\hline 4 & Jumla & $-1.4 \mathrm{E}-06$ & 0.384 & 0.40 & -0.001 & 4.40 & 1.6 & -2.35 & 0.425 & 10.5 & -2.64 & 0.49 & 0.87 & 0.24 & 0.75 & 0.86 \\
\hline
\end{tabular}

$$
\begin{aligned}
& a N+b \sum x+c \sum y+d \sum z=\sum K_{T} \\
& a \sum x+b \sum x^{2}+c \sum x y+d \sum x z=\sum K_{T} x \\
& a \sum y+b \sum y x+c \sum y^{2}+d \sum y z=\sum K_{T} y \\
& a \sum z+b \sum z x+c \sum z y+d \sum z^{2}=\sum K_{T} z
\end{aligned}
$$

These four Equations (9) to (12) were used to evaluate the regression constants $a, b, c$ and $d$ of three years for Biratnagar (BRT), Kathmandu (KTM), and Pokhara (PKR) separately and calculate the average value of respective parameters and the same was done for Jumla (JUM) by using the data of the 2 years.

\subsection{Data Analysis}

The accuracy of the estimated values was tested by using the statistical techniques for the Angstrom-Prescott model and for the new proposed model based on the definition devised by Iqbal (1983) which is as below:

$$
\begin{aligned}
& R M S E=\left[\left\{\sum_{1}^{\mathrm{n}}\left(\bar{H}_{e}-\bar{H}_{m}\right)^{2}\right\} / n\right]^{1 / 2} \\
& M B E=\left[\sum_{1}^{n}\left(\bar{H}_{e}-\bar{H}_{m}\right)\right] / n \\
& M P E=\left[\sum_{1}^{n} \frac{\bar{H}_{m}-\bar{H}_{e}}{\bar{H}_{m}} \times 100\right] / n \\
& C C=\frac{\sum\left(\bar{H}_{e}-\bar{H}_{m e}\right)\left(\bar{H}_{m}-\bar{H}_{m m}\right)}{\left[\left\{\sum\left(\bar{H}_{e}-\bar{H}_{m e}\right)^{2}\right\}\left\{\sum\left(\bar{H}_{m}-\bar{H}_{m m}\right)^{2}\right\}\right]^{1 / 2}}
\end{aligned}
$$

where $n$ is the total numbers of observations, $\bar{H}_{e}$ and $\bar{H}_{m}$ are monthly mean measured and estimated values and $\bar{H}_{m m}$ and $\bar{H}_{m e}$ are mean of measured and estimated values respectively. Calculated values of different parameters in organized form with coefficient of regression, $\mathrm{R}$ and coefficient of determinant, $\mathrm{R}^{2}$ derived from the plots for the statistical analysis are presented in the

\section{Table 2.}

The above mentioned statistical indicators are used to examine the performance of the model of solar radiation estimation. In general, low values of root mean square error (RMSE), mean bias (MBE) and mean percentage error (MPE) are desirable. RSME test provides information on the short-term performance whereas MBE and MPE test provide information on the long-term performance. The positive MBE points out the overestimation and negative MBE shows the underestimation [17] of the radiations. Ideally correlation coefficient (CC), coefficient of regression $(\mathrm{R})$ and coefficient of determinant $\left(\mathrm{R}^{2}\right)$ should be 1 for the best performance.

\section{Result and Discussion}

One year's input parameters and three/two years data were used to evaluate the regression constants, to develop the linear regressions equations and hence estimate monthly mean daily solar radiation $\left(\bar{H}_{e}\right)$ at four selected sites in Nepal as presented in Table 1. Table 3 presents the three years' monthly mean daily extraterrestrial solar radiation, clearness index, fraction of sunshine duration, ratio of average to maximum temperature and natural logarithm of average humidity at four locations in Nepal.

From the Table 3, it is manifested that clearness index and sunshine hours vary with period of the year, condition of the sky and the location. Clearness index observed minimum in July (Biratnagar 0.31, Kathmandu 
Table 3. Monthly mean of daily solar and meteorological data.

\begin{tabular}{|c|c|c|c|c|c|c|c|c|c|c|c|c|c|c|c|c|c|c|c|c|}
\hline & \multicolumn{4}{|c|}{$\bar{H}_{o}$} & \multicolumn{4}{|c|}{$\bar{K}_{T}$} & \multicolumn{4}{|c|}{$\bar{n} / \bar{N}_{d}$} & \multicolumn{4}{|c|}{$T_{a v} / T_{M}$} & \multicolumn{4}{|c|}{$L N(\overline{R H})$} \\
\hline & BRT & KTM & PKR & JUM & BRT & KTM & PKR & JUM & BRT & KTM & PKR & JUM & BRT & KTM & PKR & JUM & BRT & KTM & PKR & JUM \\
\hline Jan & 23.4 & 22.7 & 22.4 & 21.7 & 0.32 & 0.42 & 0.55 & 0.69 & 0.45 & 0.62 & 0.65 & 0.81 & 0.98 & 0.97 & 0.98 & 0.97 & 4.4 & 4.36 & 4.33 & 3.95 \\
\hline Feb & 27.8 & 27.2 & 27 & 26.3 & 0.35 & 0.42 & 0.54 & 0.63 & 0.56 & 0.67 & 0.65 & 0.69 & 0.98 & 0.97 & 0.98 & 0.97 & 4.3 & 4.29 & 4.25 & 3.95 \\
\hline May & 33.6 & 33.2 & 33.1 & 32.6 & 0.41 & 0.4 & 0.48 & 0.69 & 0.64 & 0.6 & 0.59 & 0.74 & 0.98 & 0.97 & 0.97 & 0.96 & 4.13 & 4.17 & 4.13 & 3.87 \\
\hline Apr & 38.9 & 38.7 & 38.7 & 38.4 & 0.4 & 0.42 & 0.48 & 0.59 & 0.64 & 0.64 & 0.6 & 0.56 & 0.98 & 0.97 & 0.97 & 0.97 & 4.12 & 4.04 & 4.09 & 3.95 \\
\hline May & 42.2 & 42.2 & 42.3 & 42.3 & 0.41 & 0.37 & 0.49 & 0.6 & 0.59 & 0.52 & 0.56 & 0.53 & 0.98 & 0.98 & 0.97 & 0.97 & 4.22 & 4.19 & 4.21 & 3.99 \\
\hline Jun & 43.4 & 43.6 & 43.7 & 43.8 & 0.38 & 0.34 & 0.46 & 0.57 & 0.43 & 0.44 & 0.43 & 0.39 & 0.99 & 0.98 & 0.97 & 0.97 & 4.38 & 4.28 & 4.36 & 4.05 \\
\hline Jul & 42.8 & 42.9 & 43 & 43.1 & 0.31 & 0.31 & 0.4 & 0.46 & 0.34 & 0.3 & 0.33 & 0.28 & 0.99 & 0.99 & 0.98 & 0.97 & 4.44 & 4.4 & 4.4 & 4.12 \\
\hline Aug & 40.3 & 40.2 & 40.1 & 40.1 & 0.3 & 0.31 & 0.4 & 0.4 & 0 & 0.28 & 0.36 & 0.28 & 0.99 & 0.99 & 98 & 0.97 & 4.43 & 4.42 & 4.4 & 4.14 \\
\hline Sep & 35.6 & 35.2 & 35 & 34.9 & 0.35 & 0.38 & 0.49 & 0.59 & 0.46 & 0.44 & 0.48 & 0.54 & 0.99 & 0.98 & 0.97 & 0.97 & 4.43 & 4.4 & 4.4 & 4.09 \\
\hline Oct & 29.6 & 29.1 & 28.7 & 28.4 & 0.42 & 0.48 & 0.62 & 0.71 & 0.61 & 0.64 & 0.73 & 0.82 & 0.98 & 0.98 & 0.97 & 0.97 & 4.37 & 4.37 & 4.32 & 3.95 \\
\hline Nov & 24.4 & 23.7 & 24.1 & 22.8 & 0.44 & 0.5 & 0.63 & 0.73 & 0.7 & 0.69 & 0.79 & 0.84 & 0.98 & 0.97 & 0.97 & 0.96 & 4.33 & 4.39 & 4.28 & 3.88 \\
\hline Dec & 22 & 21.3 & 21 & 20.3 & 0.43 & 0.47 & 0.56 & 0.7 & 0.62 & 0.6 & 0.7 & 0.82 & 0.98 & 0.97 & 0.98 & 0.96 & 4.38 & 4.41 & 4.31 & 3.86 \\
\hline
\end{tabular}

0.31, Pokhara 0.4 and Jumla 0.46) and August indicating the overcast/cloud covered skies and more aerosols and maximum value was observed in November (Biratnagar 0.44, Kathmandu 0.5, Pokhara 0.63 and Jumla 0.73) and October suggesting the more clear skies with fewer aerosols. Similarly high values of sunshine hours were observed in November at all sites and among them highest value (0.84) was at Jumla (latitude $29.283^{\circ}$, and altitude $2300 \mathrm{~m}$ ) and the least of maximum values $(0.69)$ was at Kathmandu (latitude $27.7^{\circ}$, and altitude $1337 \mathrm{~m}$ ) because of high clearness index/sunshine hours. The values are minimum in July and August due to less clearness index/sunshine hours. Unexpected least values at Kathmandu indicate the more hazy and pollutant particulates in the atmosphere above the Kathmandu valley.

Table 4 presents the measured and estimated monthly mean daily global solar radiation at four different sites of Nepal where their altitude varies from $72 \mathrm{~m}$ to $2300 \mathrm{~m}$ above the sea level. These values were estimated by using the Angstrom-Prescott model and by the new proposed model.

The minimum measured and estimated monthly mean daily radiation on the horizontal surfaces for all sites were observed in January characterized by more cloudy/ foggy days. And maximum values were observed in May at Biratnagar, Pokhara and Jumla and in April at Kathmandu which is characterized by more clear skies and less aerosols. Among four sites, maximum radiation (measured $\bar{H}_{m}=25.21 \mathrm{MJ} / \mathrm{m}^{2}$. day and estimated $\bar{H}_{e}$ $=25.25 \mathrm{MJ} / \mathrm{m}^{2} \cdot$ day $)$ was observed at Jumla $(2300 \mathrm{~m}$ above the sea level) and minimum radiation (measured $\bar{H}_{m}=7.508 \mathrm{MJ} / \mathrm{m}^{2} \cdot$ day and estimated $\bar{H}_{e}=7.97 \mathrm{MJ} /$ $\mathrm{m}^{2}$.day) was observed at Biratnagar $(72 \mathrm{~m}$ above the sea level). The result showed the altitude and location de- pendency of the radiation. The table also shows the close agreement of the measured and estimated values by the new proposed model.

The least values of root mean square error RMSE, mean bias error MBE and mean percentage error MPE indicate the best linear regression relations to estimate global solar radiation at Biratnagar, Kathmandu, Pokhara and Jumla in Nepal.

In this study, three additional statistical indicators were used to evaluate the accuracy and performance of new proposed model. The highest value of $\mathrm{R}(=0.97$ at Pokhara) and minimum value of $\mathrm{R}(=0.87$ at Jumla), the higher correlation coefficient CC ( 0.86 at Jumla to 0.99 at Pokhara) and the Figures from 1-5 of the plots of global solar radiations estimated by the Angstrom-Prescott and new proposed model proved the higher performance of the new proposed model in comparison to Angstrom-Prescott model and the value estimated by Poudyal, et al. [18].

\section{Conclusions}

Rational and accurate solar energy databases, essential for designing, sizing and performing the solar energy systems in any part of the world, are not easily accessible in different localities of Nepal. The database of the solar radiation at any locations is very useful for that particular locality as well as for the broader world community [14] for a sustainable future energy.

Important finding of this work is the linear regression analysis of the global solar radiation, sunshine durations, temperature and relative humidity data through least square technique that lead to the development of this new proposed model showing the best 
Temperature and Relative Humidity

Table 4. Monthly mean daily measured and estimated global solar radiation.

\begin{tabular}{ccccccccccccc}
\hline Months & \multicolumn{3}{c}{ Biratnagar Radiation } & \multicolumn{3}{c}{ Kathmandu Radiation } & \multicolumn{3}{c}{ Pokhara Radiation } & \multicolumn{3}{c}{ Jumla Radiation } \\
\hline & $\bar{H}_{m}$ & $\bar{H}_{\text {eAng }}$ & $\bar{H}_{\text {eNew }}$ & $\bar{H}_{m}$ & $\bar{H}_{\text {eAng }}$ & $\bar{H}_{\text {eNew }}$ & $\bar{H}_{m}$ & $\bar{H}_{\text {eAng }}$ & $\bar{H}_{\text {eNew }}$ & $\bar{H}_{m}$ & $\bar{H}_{\text {eAng }}$ & $\bar{H}_{\text {eNew }}$ \\
\hline JAN & 7.51 & 6.90 & 7.97 & 9.54 & 11.32 & 10.30 & 12.31 & 13.40 & 11.95 & 15.04 & 16.56 & 15.15 \\
FEB & 9.82 & 10.36 & 10.41 & 11.35 & 14.93 & 12.71 & 14.5 & 16.16 & 14.15 & 16.75 & 17.00 & 17.16 \\
MAR & 13.92 & 14.41 & 13.98 & 13.21 & 16.02 & 14.40 & 15.93 & 17.93 & 16.24 & 22.38 & 22.71 & 21.98 \\
APR & 15.59 & 16.85 & 16.45 & 16.39 & 20.24 & 16.95 & 18.56 & 21.33 & 18.94 & 22.81 & 20.29 & 23.44 \\
MAY & 17.19 & 16.77 & 16.91 & 15.53 & 17.33 & 17.18 & 20.9 & 21.72 & 20.72 & 25.21 & 20.9 & 25.26 \\
JUN & 16.61 & 12.19 & 15.27 & 15.01 & 15.06 & 16.99 & 20.06 & 17.48 & 20.31 & 24.97 & 16.00 & 24.08 \\
JUL & 13.12 & 9.42 & 14.15 & 13.41 & 9.6 & 15.16 & 17.25 & 12.95 & 18.62 & 19.99 & 11.08 & 21.92 \\
AUG & 12.92 & 10.51 & 13.71 & 12.57 & 8.48 & 14.07 & 17.8 & 13.24 & 17.81 & 19.23 & 10.16 & 20.3 \\
SEP & 12.46 & 10.83 & 12.43 & 13.40 & 12.4 & 14.13 & 17.16 & 15.62 & 17.06 & 20.54 & 17.5 & 21.08 \\
OCT & 12.54 & 12.18 & 11.26 & 13.89 & 15.16 & 13.46 & 17.7 & 19.27 & 16.13 & 20.03 & 21.75 & 20.05 \\
NOV & 10.51 & 11.49 & 9.61 & 11.67 & 13.26 & 11.36 & 15.21 & 17.48 & 13.9 & 16.73 & 17.97 & 16.25 \\
DEC & 9.39 & 9.12 & 8.17 & 10.04 & 10.36 & 9.66 & 11.67 & 13.49 & 11.504 & 14.31 & 15.60 & 14.21 \\
\hline
\end{tabular}

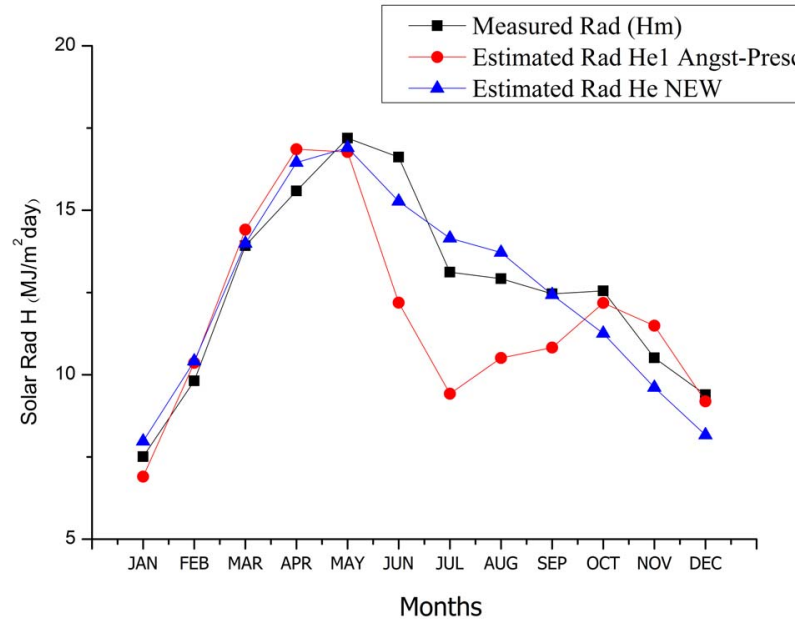

(a)

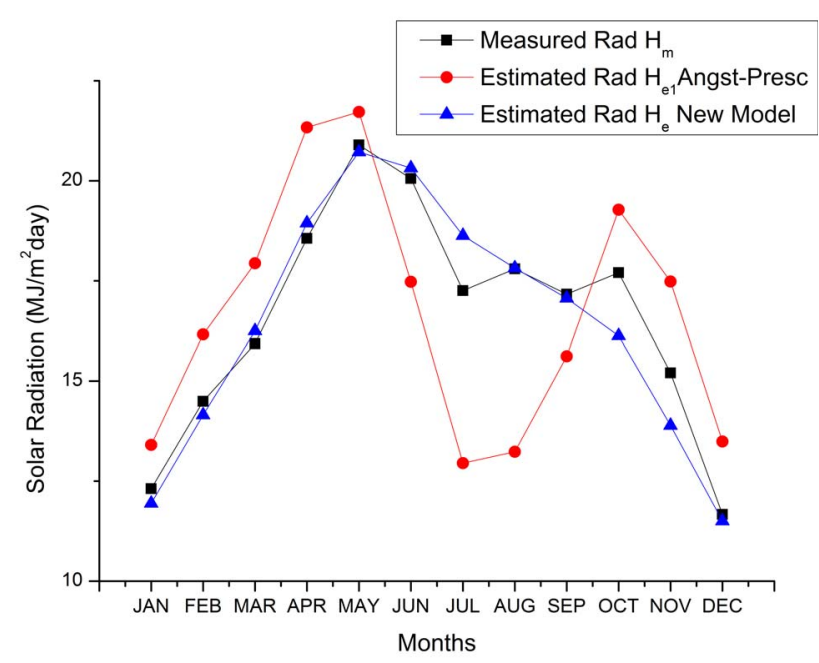

(c)

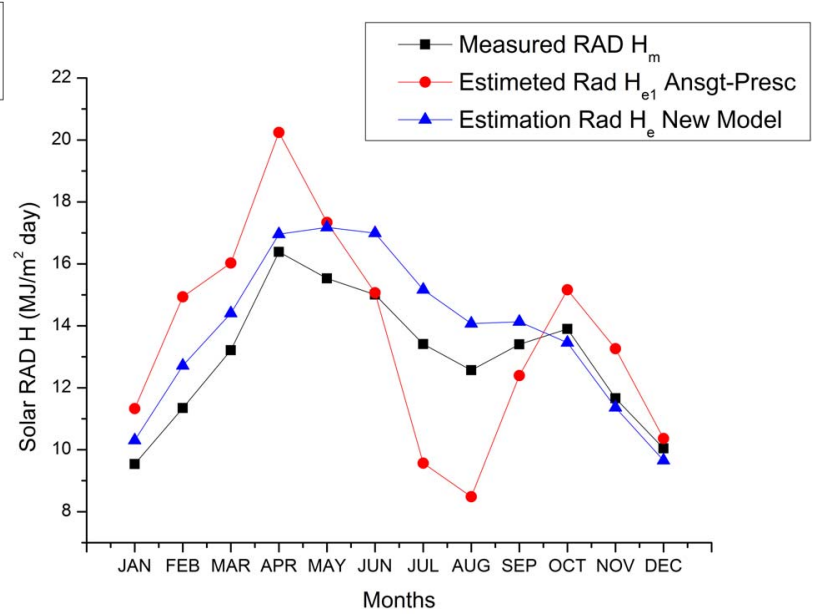

(b)

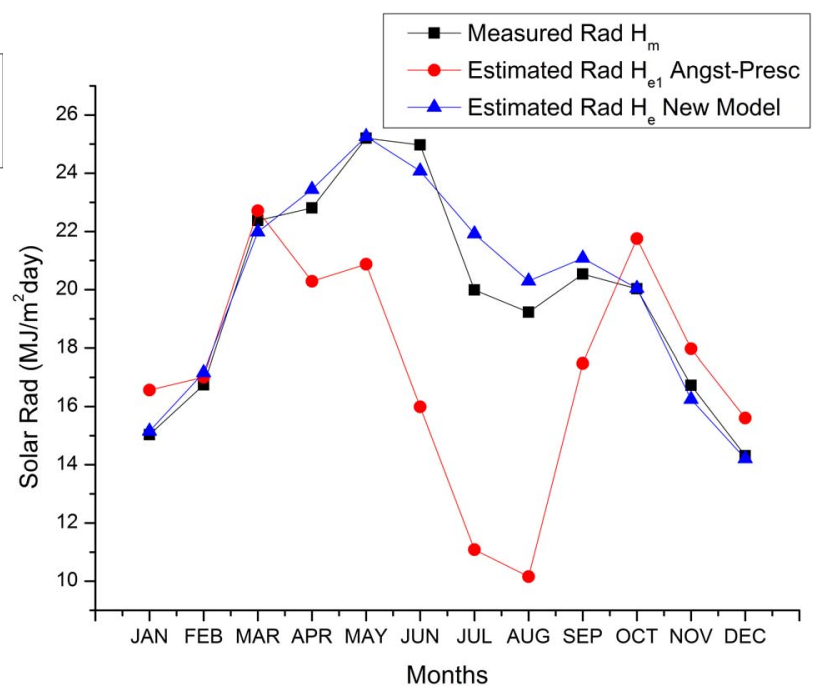

(d)

Figure 1. (a) Variation of radiation with months for Biratnaga; (b) Variation of radiation with months for Kathmandu; (c) Variation of radiation with months for Pokhara; (d) Variation of radiation with months for Jumla. 

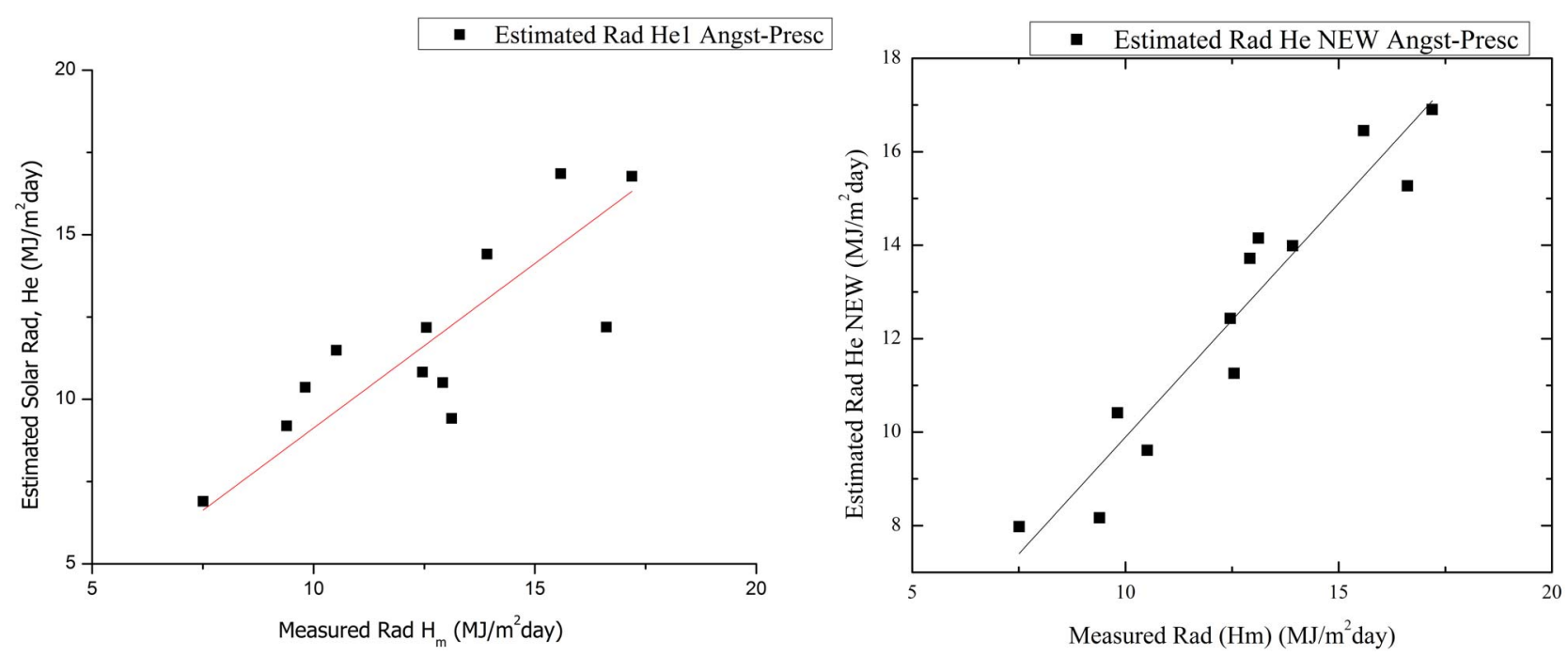

Figure 2. Measured $\left(\bar{H}_{m}\right)$ versus estimation global solar radiation $\left(\bar{H}_{e}\right)$ by Angstrom-Prescott model and new model for Biratnagar.
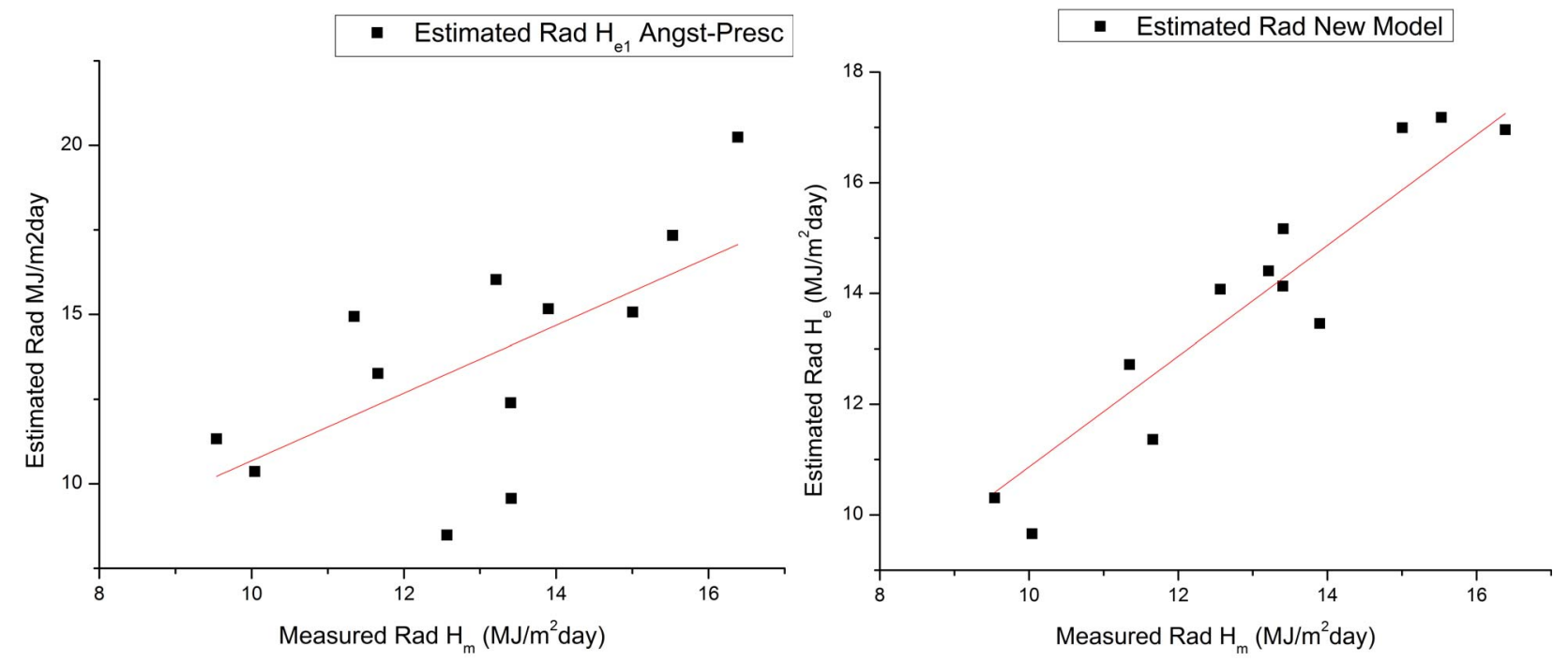

Figure 3. Measured $\left(\bar{H}_{m}\right)$ versus estimation global solar radiation $\left(\bar{H}_{e}\right)$ by Angstrom-Prescott model and new model for Kathmandu.

correlation for Biratnagar, Kathmandu, Pokhara and Jumla (from east to west) between measured and estimated values in Nepal. The linear regression relations to estimate/predict the global solar radiation on the horizontal surface of Biratnagar, Kathmandu, Pokhara and Jumla are as below:

$$
\begin{aligned}
\frac{\bar{H}_{m}}{\bar{H}_{O}}= & -2 E(-07)+0.162\left(\frac{\bar{n}}{\bar{N}_{d}}\right) \\
& +1.032\left(\frac{\bar{T}_{a v}}{\bar{T}_{M}}\right)-0.168 \ln (\overline{R H})
\end{aligned}
$$

$$
\begin{aligned}
\frac{\bar{H}_{m}}{\bar{H}_{O}=} & -1 E(-04)+0.324\left(\frac{\bar{n}}{\bar{N}_{d}}\right) \\
& -0.09\left(\frac{\bar{T}_{a v}}{\bar{T}_{M}}\right)+0.08 \ln (\overline{R H}) \\
\frac{\bar{H}_{m}}{\bar{H}_{O}}= & -8 E(-06)+0.337\left(\frac{\bar{n}}{\bar{N}_{d}}\right) \\
& -0.21\left(\frac{\bar{T}_{a v}}{\bar{T}_{M}}\right)+0.12 \ln (\overline{R H})
\end{aligned}
$$



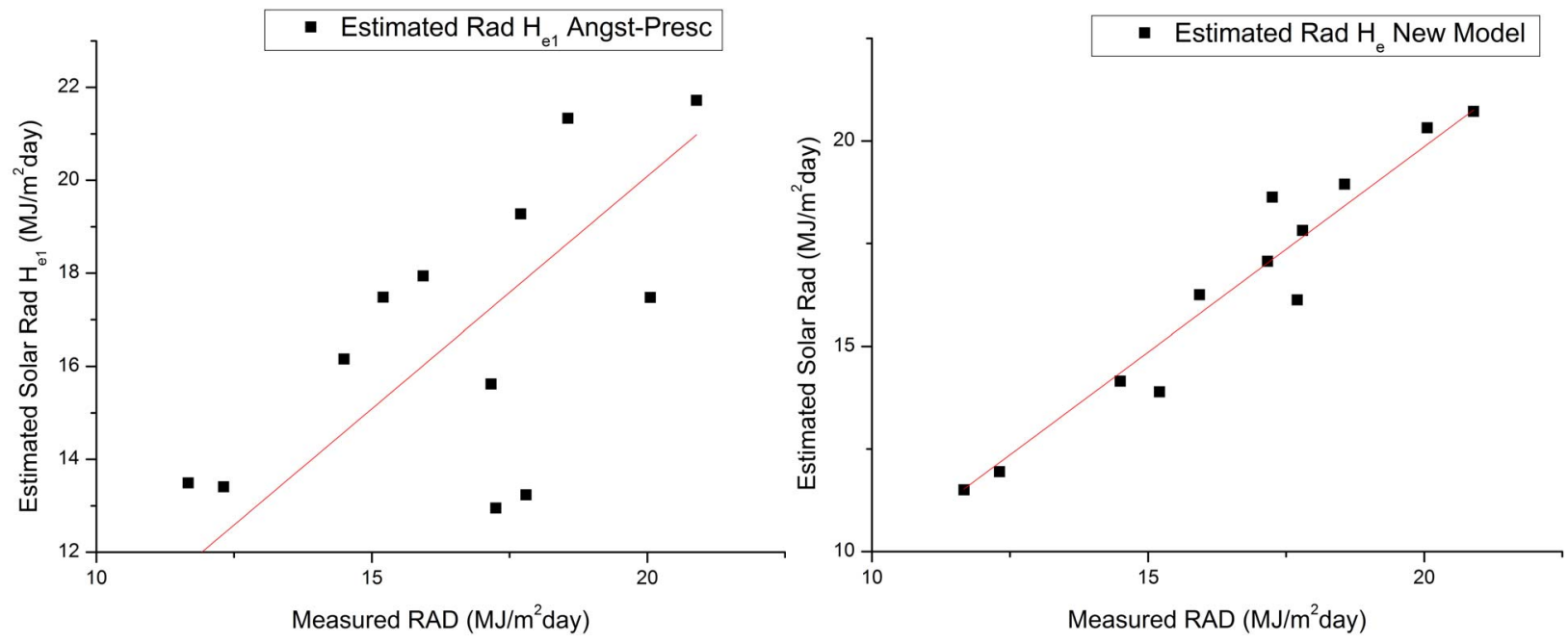

Figure 4. Measured $\left(\bar{H}_{m}\right)$ versus estimation global solar radiation $\left(\bar{H}_{e}\right)$ by Angstrom-Prescott model and new model for Pokhara.
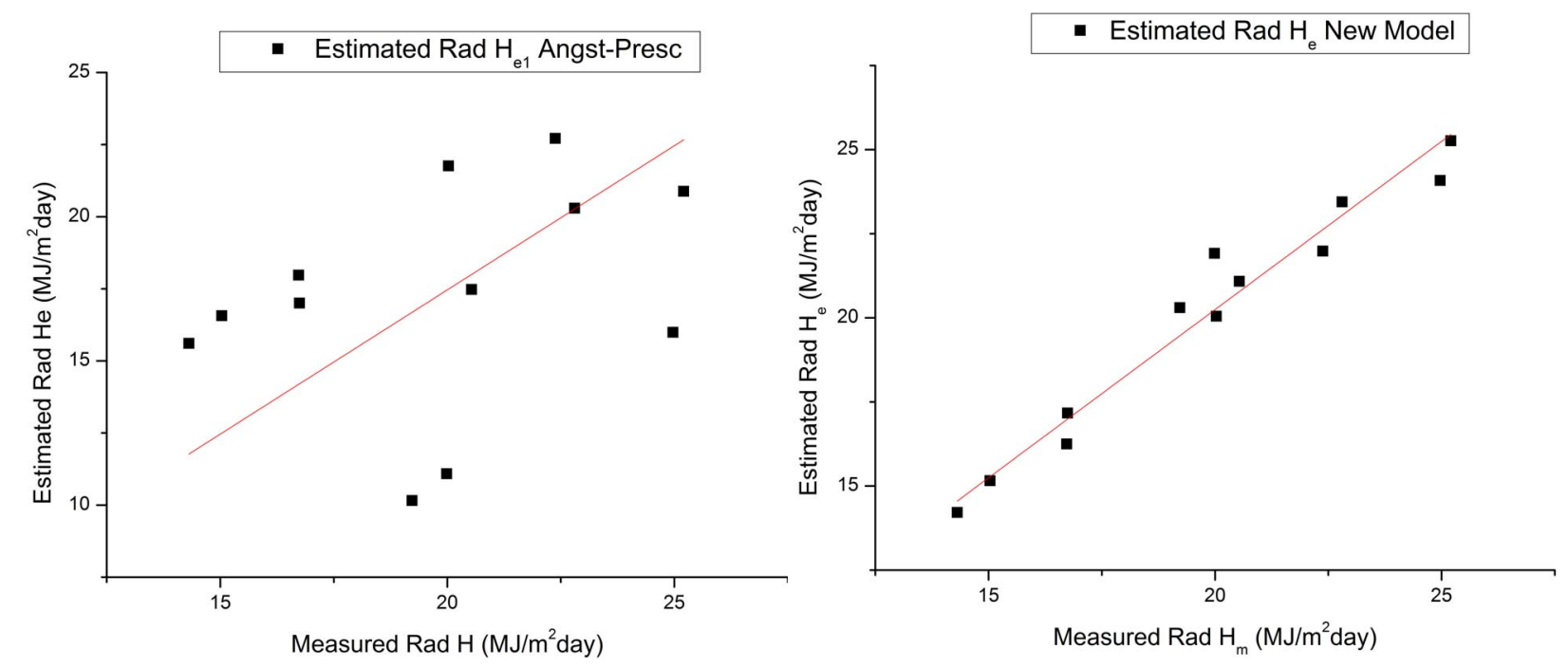

Figure 5. Measured $\left(\bar{H}_{m}\right)$ versus estimation global solar radiation $\left(\bar{H}_{e}\right)$ by Angstrom-Prescott model and new model for Jumla.

$$
\begin{aligned}
\frac{\bar{H}_{m}}{\overline{\bar{H}}_{O}}= & -1.4 E(+07)+0.384\left(\frac{\bar{n}}{\overline{\bar{N}}_{d}}\right) \\
& +0.40\left(\frac{\bar{T}_{a v}}{\bar{T}_{M}}\right)-0.001 \ln (\overline{R H})
\end{aligned}
$$

respectively.

Excellent agreement has been found between measured and estimated global solar radiation predicted by linear regression equations (new proposed model). The statistical/error analysis techniques/examination also confirm the better performance of the model at those sites; they cover almost all parts of Nepal.
Jumla (high altitude location) is the place where high potential of global solar radiation was observed and least value of radiation was observed at Biratnagar (low altitude location). But it is also obvious that ample solar radiation is observed at all sites in Nepal. The new proposed model may then be used to estimate daily and monthly mean daily solar radiation for the locations of similar geographical/meteorological characteristics and also can be used to estimate the missing daily/monthly mean daily solar radiation at the respective site. This study recommends that Pokhara, Jumla and places having similar altitude/geographical/meteorological parameters, rather than terai region, are suitable for solar farm- 
ing activities in Nepal.

\section{Acknowledgements}

Authors gratefully express sincere thanks to University Grant Commission, Nepal for providing assistance in the form of scholarship and assistantship for this research work and are indebted to Solar Radiation and Aerosol in Himalaya Region (SAHR) project, Pulchowk, Nepal and Department of Hydrology and Meteorology/GoN for making the data available.

\section{REFERENCES}

[1] WECS, "Energy Sector Synopsis Report 2010," Water and Energy Commission Secretariat, Kathmandu, Government of Nepal, 2010.

[2] Ministry of Environment, Government of Nepal, "National Adaptation Program of Action 2010," NAPA TWG Draft Summary Report, 2010.

[3] NEA, "Nepal Electricity Authority Report 2011," Ministry of Energy, Government of Nepal, 2011.

[4] "Nepal Energy Situation," 2013. https://energypedia.info/wiki/Nepal_Energy_Situation

[5] K. N. Poudyal, B. K. Bhattarai, B. K. Sapkota and K. Berit, "Estimation of Global Solar Radiation Using Clearness Index and Cloud Transmittance Factor at Trans-Himalayan Region in Nepal," Energy and Power Engineering, Vol. 4, No. 6, 2012, pp. 415-421. doi:10.4236/epe.2012.46055

[6] O. Sunday, "Estimation of Global and Diffuse Solar Radiations for Selected Cities in Nigeria," International Journal of Energy and Environmental Engineering, Vol. 2, No. 3, 2011, pp. 11-33.

[7] Solar Energy Research Laboratory, Department of Physics, Silpakorn University, Thailand, "Assessment of Solar Energy Potentials for Lao People's Democratic Republic," Department of Alternative Energy Development and Efficiency, Thailand, Department of Electricity, Lao PDR, 2010.
[8] M. Chegaar and A. Chibani, "A Simple Method for Computing Global Solar Radiation," Rev. Energ.Ren.Chemss, 2000, pp. 111-115.

http://www.docin.com/p-180112482.html

[9] L. S. Murry, "Fundamental of Atmospheric Physics," Academic Press, New York, 1996.

[10] M. Iqbal, “An Introduction to Solar Radiation," Academic Press, New York, 1983.

[11] R. H. B. Excell, "The Intensity of Solar Radiation," King Mongkut's University of Technology Press, Thorburi, 2000.

[12] C. Augustine and M. N. Nnabuchi, "Relationship between Global Solar Radiation and Sunshine Hours for Calabar, Port Harcourt and Enugu, Nigeria," International Journal of Physical Sciences, Vol. 4, No. 4, 2009, pp. 182-188.

[13] S. S. Chandel, R. K. Agrawal and A. N. Pandey, "New Correlation to Estimate Global Solar Radiation on Horizontal Surfaces Using Sunshine Hours and Temperature Data for Indian Sites," Journal of Solar Engineering, Vol. 127, No. 3, 2005, pp. 417-420. doi:10.1115/1.1877512

[14] A. A. Dehghan, F. Besharat and A. R. Faghig, "Empirical Models for Estimating Global Solar Radiation: A Review and Case Study," Renewable and Sustainable Energy Review, Vol. 21, 2013, pp. 798-821. doi:10.1016/j.rser.2012.12.043

[15] J. E. Ekpe and M. N. Nnabuchi, "Solar Radiation in Onitsha: A Correlation with Average Temperature," Scholarity Journals of Biotechnology, Vol. 1, No. 5, 2012, pp. 101-107.

[16] B. Murray, "Correlation of Solar Radiation Withclouds," Solar Energy, Vol. 12, No. 1, 1961, pp. 417-420.

[17] C. K. Panday and A. K. Katiyar, "Temperature Base Correlation for the Estimation of Global Solar Radiation on Horizontal Surface," International Journal of Energy and Environment, Vol. 1, No. 4, 2010, pp. 737-744.

[18] K. N. Poudyal, B. K. Bhattarai, B. K. Sapkota and K. Berit, "Estimation of Global Solar Radiation Using Sunshine Duration in Himalaya Region," Research Journal of Chemical Sciences, Vol. 2, No. 11, 2012, pp. 20-25. 